\title{
Recurrent Carcinoma
}

National Cancer Institute

\section{Source}

National Cancer Institute. Recurrent Carcinoma. NCI Thesaurus. Code C7619.

The reemergence of a carcinoma after a period of remission. 